\title{
Scientific data must be made available to all
}

\section{An internationally binding regulation should be the first step towards securing vital data.}

Sir-Recent correspondents (see for example, K. Alverson and M. Eakin, and M. Boulter, Nature 412, 269; 2001) emphasize the importance of general repositories for scientific data. They point out the lack of appropriate financing for scientific data management and the need for thematically related scientificinformation systems to be networked, which is technically feasible.

The current problem resides deeper. To enact global agreements such as the Kyoto protocol, for example, decision-makers are required to pursue policies that cover many different, yet plausible, estimates of the likelihood of alternative, future climate development. These climate-change scenarios are frequently derived from climate models, whose correctness can be measured only by access to raw data.

The necessary database infrastructure was created as early as the 1950s, when the International Council of Scientific Unions set up the World Data Center (WDC) system (www.ngdc.noaa.gov/wdc). These centres are for the international exchange of solar, geophysical and related environmental data on a long-term basis, and are to assist principal investigators (PIs) in broad data management. Yet there are no international regulations requiring scientists to store results as raw data and accompanying meta-information in this or any other publicly accessible archive.

Some scientific journals and funding agencies encourage PIs or authors to submit raw data or support data sharing. Yet the US National Science Foundation (NSF) is the only funding organization that insists on this. In its information on submitting climate-related proposals for its Earth System History Program (www. nsf.gov/pubs/2000/nsf0011/nsf0011.html), the NSF says: "Each proposal must adhere to the USGCRP [US Global Change Research Program] data management policy .... and the policies applying to recipients of Federal funding in the geosciences. Unless otherwise specified in the proposal, the $[\mathrm{PI}]$ will be responsible for ensuring that all data generated by the funded project will be documented and submitted to the World Data Center".

Our example of climate-change models is but one of many where raw data are needed for accurate scientific assessment in the long term. An internationally binding regulation that adheres to WDC principles is required. It should guarantee that all scientific data are archived and freely available. Because some PIs still refuse to archive data individually in appropriate databases such as the WDC, still refuse to make their published data publicly available as raw data, and still ignore the potential benefit from networking through WDCs, additional financial and temporal effort must be spent to gain access to these data.

Until a free-access global repository can be set up, this may be the best first step. The long-term goal must be to secure the world's stock of valuable data, and to overcome practical difficulties in so doing. Nicolas Dittert ${ }^{\star}$, Michael Diepenbroek $\dagger$, Hannes Grobe $\ddagger$

${ }^{*}$ SINOPS Project Office France, Institut Universitaire Européen de la Mer, UMR 6539 - LEMAR, Place

Nicolas Copernic, Plouzané F-29280, France

†World Data Center for Marine Environmental Sciences, Klagenfurterstr., Bremen D-28359, Germany $\ddagger$ PANGAEA Network for Geological and Environ-

mental Data, Alfred Wegener Institute for Polar and Marine Research, Bremerhaven D-27515, Germany

\section{Speak out against wrong done in your name}

Sir — Edgar Pick in his Correspondence "Science is universal, not part of any religion" (Nature 414, 249; 2001) is right in pointing out that simply trying to engage with 'Islamic' science is not a way for western (presumably 'non-Islamic') scientists to contribute to the struggle against terrorism. However, he is wrong is saying "the evil of killing people ... hardly requires a restatement" by Islamic scholars.

The terrorists who flew planes into the World Trade Center may very well be "an international gang of well-financed criminals" but they apparently carried out these acts in the name of Islam. If a group of deranged scientists began slaughtering innocent people in the name of cell biology, then I would be the first to stand up and say "Hang on a minute, not all cell biologists adhere to this view".

To the millions in the non-Islamic world who have neither Pick's education nor his knowledge of Islam, the statements of condemnation by Islamic leaders and scholars provided essential reassurance and may have helped deflect retributive acts by the more thuggish elements of our society.

Stephen E. Moss

Division of Cell Biology, Institute of Ophthalmology, University College London, Bath Street,

London EC1V 9EL, UK

\section{Chimaeric mice on the road towards stem cells}

Sir - In his engaging Commentary "IVF and the history of stem cells" Bob Edwards gives me undue credit in asserting that I produced the world's first mouse chimaera. Unquestionably, it is Krzysztof Tarkowski who should be credited with this. He aggregated mechanically denuded mouse morulae in pairs to obtain giant blastocysts, some of which developed normally to term following transfer to uterine foster-mothers ${ }^{2}$. Although perinatal losses were inexplicably high, seven of nine available young showed a mixture of pigmented and unpigmented cells in their eyes, in accordance with the genotypes of the morulae that were combined $^{3}$. Subsequently, Beatrice Mintz introduced various technical improvements that enabled chimaeric mice to be produced routinely ${ }^{4}$.

My contribution was to show that similar chimaeras could be obtained by transplanting cells between blastocysts ${ }^{5}$. This was a refinement that enhanced the value of such organisms for studying development $^{6}$ and was later adopted as the standard way of obtaining germline transmission of genetically modified embryonic stem cells.

Richard Gardner

Department of Zoology, University of Oxford, Oxford OX1 3PS, UK
1. Edwards, R. G. Nature 413, 349-351 (2001).
2. Tarkowski, A. K. Nature 190, 857-860 (1961).
3. Tarkowski, A. K. NCI Mongraph 11, 51-71 (1962).
4. Mintz, B. Science 138, 594-595 (1962).
5. Gardner, R. L. Nature 220, 596-597 (1968).
6. Gardner. R. L. BioEssays 20, 168-190 (1997).

\section{The perils of peer review}

Sir - Your News feature "Peers under pressure" (Nature 413, 102-4; 2001) on the hoary old chestnut of peer review reinforces my decades-old comparison of this ritual to the Latin mass. Obviously many (Protestant?) leaders, including most of the best-known scientists such as Nobel laureates, regard peer-review as a great hindrance to good science (the gospel?). Many excellent journals (churches?), such as the Proceedings of the Royal Society and Proceedings of the National Academy of Sciences managed in my opinion very well without it for a long time. An enormous amount of the best science has been and is 
being run without benefit of this rubric, as is the worldwide patent system.

The allusion in your Feature to Paul Chu and the 1:2:3 superconductor paper — the contents of which had clearly reached rival research groups before publication, and in which "ytterbium" was changed to "yttrium" at the last minute points to but one of the very minor ineradicable defects of the peer-review system, that we can confirm. At the time that paper was submitted, several of its authors, including one of us (J. R. A.) who had made the very first samples of 1:2:3 at the University of Alabama, had a conversation with his Alabama colleagues and Dr Chu of the University of Houston, at which the wise decision was made to substitute $\mathrm{Yb}$ for $Y$ in the text. The galley proof ( still in J.R.A.'s possession) shows $\mathrm{Yb}$, not $\mathrm{Y}$, in all four places where it appears. The full chemical name of ytterbium — and, subsequently, yttrium - was conveniently omitted from the text of the paper so that the amendments before final printing could be confined only to the symbols. This stratagem was also alluded to in the Materials Research Society videotapes on the history of the 1:2:3 discovery, organized by one of us (R.R.). Everyone except the true believers knows that it is your nearest competitors (adversaries?) who often 'peer' review your paper. Hence, you must protect yourself by this and other subterfuges, like proposing work you have just completed.

Yet this is but a minor defect in the peer-review system. The enormous waste of scientists' time, and the absolute, ineluctable bias against innovation, are its worst offences.

'Review by competitors' is an all-tooaccurate description of this system, wreaking devastation on papers and proposals in science. Financial and selfinterest disclosures, such as competing for the same funds, should surely now be required of peers.

More: where is the evidence for any benefits from peer review? Recently, Nature (Nature 412, 751; 2001) and most medical journals have been forced to require financial disclosures by authors to deal with the fact that peer review could do nothing to avoid the widely acknowledged contamination of the literature. This was illustrated by papers published about the drugs Vioxx and Celebrex - just one example picked up by the secular press (Washington Post, 5 August 2001; Wall Street Journal, 22 August 2001) in frontpage stories after a paper in the Journal of the American Medical Association (J. Am. Med. Assoc. 286, 8; 2001) reported that these popular painkillers carried a risk of cardiovascular problems. The newspapers reported that cardiovascular risks from
Celebrex had been simply "omitted" from an earlier paper (J. Am. Med. Assoc. 284, $10 ; 2000)$. All sixteen authors of the earlier paper — including faculty from eight universities - were either employees, funded by or consultants of the manufacturers. What use was peer review here?

Finally, Nature should not repeat the old canards such as: "despite the problems thrown up by peer review, no serious alternative has yet been proposed". Nonsense. They have not only been proposed but have been in regular use worldwide for a very long time. The users include the world's largest research agency, the US Department of Defense, and industrial research worldwide.

Rustum Roy*, James R. Ashburn $\dagger$

${ }^{*}$ The Pennsylvania State University, 102 Materials Research Laboratory, University Park, Pennsylvania 16802, USA

†Elmco, 60 Technology Drive, Building 1, Suite N, Huntsville, Alabama 35805, USA

\section{Carrots, not sticks, give best 'quality assurance'}

Sir - I was interested in your News story "Proposed scheme will scrutinize student supervisors" (Nature 413, 761; 2001) describing the plans by the Biotechnology and Biological Sciences Research Council (BBSRC) and the Higher Education Funding Council for England (HEFCE) to improve training and standards for the supervisors of postgraduate students in the United Kingdom.

Raising the standards for postgraduate student supervision is a good thing. However, the rush by government and other higher-education bodies to introduce 'quality assurance' wherever conceivable, with initiatives such as the Research Assessment Exercise and the Institute for Learning and Teaching, appears little more effective in alleviating the real problems than sticking a plaster over a gangrenous wound.

The acknowledged difficulty in enrolling well-qualified postgraduate students in the United Kingdom — and the reason so many $\mathrm{PhDs}$ do not seek employment in their subjects - probably stems from the lack of an equitable career structure in higher education. I cannot think of another career where the most experienced practical practitioners, postdocs, live from short-term contract to short-term contract and risk being priced out of the job market when they have acquired years of experience.

This situation needs to be urgently remedied. Introduce a nationally recognized training scheme which allows research trainees to build a recognized skills portfolio. This would help them secure jobs as they progress through their career - even if this means reducing the number of $\mathrm{PhD}$ places. Training could include skills such as grant writing, staff management, project management and writing papers, in addition to traditional technical hands-on abilities.

Even when postdoctoral trainees do manage to get academic positions, they find that, since the late seventies, academic salaries have fallen far below those of comparable professions and of the private sector. Students graduating with an undergraduate degree and saddled with debts of, on average, $\mathfrak{E} 16,000$ (US\$22,600) are hardly likely to consider further years of penury and job insecurity worth the risk. Unless the government has the foresight to address these overarching problems, the future of the higher education sector and the intellectual skills base of the United Kingdom looks bleak. In the end you get the system that you pay for.

It would also be of help if carrots were used instead of sticks. How about HEFCE giving a pay rise to staff who do meet their new training standards? I would also be intrigued to know if this new spirit of 'above-board correctness' extends to paying realistic fees for external examiners of $\mathrm{PhD}$ theses. Currently the average fee is $\mathfrak{E} 120$ to examine a $\mathrm{PhD}$ thesis; the Association of University Teachers recommends a fee of $\mathfrak{E} 450$, which is not unreasonable. Try asking a management consultant to read about 250 pages, consult libraries and travel to crossexamine someone for this fee. The last time that I heard of an external examiner asking for $\mathfrak{E} 450$, the candidate's supervisor was told to find another examiner who would accept the lower fee.

\section{Roddie McKenzie}

Department of Dermatology, University of Edinburgh, Lauriston Building RIE, Edinburgh EH3 9YW, Scotland, UK

\section{Motion and meaning}

Sir - In his News and Views Feature

"Where drunkards hang out" (Nature 413, 686-687; 2001), Ian Stewart states

"Brownian motion is no longer important in its original physical context". I beg to differ. Analysis of diffusion as brownian motion is central to understanding the physics of diffusion-controlled biochemical reactions, such as ion permeation through protein channels, to take one example.

\section{Eric Jakobsson}

Department of Molecular and Integrative Physiology, National Center for Supercomputing Applications, University of Illinois, Urbana,

Illinois 61801, USA 